\title{
INTERACCIONES ENTRE CULTURA(S) Y RELIGIÓN EN MINORÍAS SOCIO-RELIGIOSAS. EL CASO DE LOS MUSULMANES Y EVANGÉLICOS-PENTECOSTALES EN ESPAÑA ${ }^{1}$
}

\section{Cultures and religion interactions among socio-religious minorities. Muslims and Evangelical Pentecostals' case in Spain}

\author{
Antonio Montañés* \\ * Universidad Complutense de Madrid y National University of Ireland-Maynooth \\ amjsociologia@gmail.com
}

\section{Palabras clave \\ Cultura \\ Minorías Religiosas \\ Pluralismo Religioso \\ Pérez-Agote \\ Teoría de la \\ diferenciación funcional de esferas}

Keywords

Culture

Religious MInorities

Religious Plurality

Pérez-Agote

Theory of functional

differentiation of

spheres

\begin{abstract}
Resumen
En el presente artículo, homenaje a la obra del profesor Pérez-Agote, abordo dos de las temáticas que han atraído la atención del sociólogo en la última década: la secularización y el pluralismo religioso. Se intenta contribuir particularmente al estudio del segundo fenómeno, pluralismo religioso, en relación a las dos religiones no católicas más importantes en España en la actualidad, Islam y Evangelismo-Pentecostal, mediante el análisis de cómo, bajo qué circunstancias y en qué medida la interacción (diferenciación/des-diferenciación) cultura-religión es relevante para la supervivencia de la religión en situación de minoría social.
\end{abstract}

Montañés, A., 2015, "Interacciones entre cultura(s) y religión en minorías socio-religiosas. El caso de los musulmanes y evangélicos-pentecostales en España", en Papeles del CEIC, vol. 2015/3, no 142, CEIC (Centro de Estudios sobre la Identidad Colectiva), Universidad del País Vasco, http://dx.doi.org/10.1387/pceic.14604

Recibido: 06/2015; Aceptado: 07/2015

$1 \mathrm{El}$ autor desea hacer constancia que este trabajo no podría haber sido posible sin la ayuda a la Formación de Personal Investigador (FPI-BES-2011-043768) que me fue concedida por el Ministerio de Economía y Competitividad del Gobierno Español. El artículo es una reformulación de la ponencia "Etno-religiones en sociedades plurales" presentada en las jornadas "A propósito de la obra de Alfonso Pérez-Agote" celebradas los días 28 y 29 de noviembre de 2014 organizadas por los grupos de investigación GRESCOTRANSOC (Universidad Complutense) y CEIC (Universidad del País Vasco) Agradezco a todos los asistentes, así como al evaluador anónimo de la revista y a los editores, sus reflexiones, correcciones, comentarios y propuestas. 
1. UN PROGRAMA DE INVESTIGACIÓN SOBRE LAS RELACIONES SOCIEDAD-RELIGIÓN EN PAÍSES DE HISTÓRICA MAYORÍA CATÓLICA EN GENERAL Y EN ESPAÑA EN PARTICULAR

En este artículo examinaremos una temática que ha ocupado el centro de la labor investigadora de Alfonso Pérez-Agote desde, al menos, la última década: el fenómeno religioso. Con ello me sumo a las líneas de investigación del programa en proceso sobre las transformaciones en los países europeos de histórica tradición católica que el autor y el Grupo a nivel europeo que él mismo fundó y coordina, Groupe Européen de Recherche Interdisciplinaire sur le Changement Religieux (GERICR), llevan realizando en los últimos años (Pérez-Agote, 2012a; Dobbelaere y Pérez-Agote, 2015). Para el caso español, este programa de investigación se ancla en la delineación de tres lógicas o procesos sociológicos fundamentales, que caracterizan, según el autor, las relaciones religión-sociedad española en el siglo XXI (Pérez-Agote, 2010): (i) el análisis cuantitativo de la evolución histórica de las creencias y las práctica religiosas (Pérez-Agote y Santiago, 2005; Pérez-Agote, 2012b); (ii) los sucesivos vaivenes de las relaciones entre las esferas política y religiosa, que en España históricamente toman principalmente la forma Iglesia Católica-Estado (Pérez-Agote, 2008); y (iii) el estudio del "Nuevo pluralismo religioso" en España (Pérez-Agote y Santiago, 2009).

Repasando la contribución a la disciplina que el sociólogo ha realizado en la última década, propondré que la arquitectura del programa de investigación de Pérez-Agote se edifica sobre el análisis de las interrelaciones entre dos fenómenos, la secularización y el pluralismo religioso, y tres dimensiones: prácticas y creencias religiosas; el papel público de las Instituciones religiosas, especialmente político, pero también cívico y comunitario; y la relación de la religión con el resto de esferas societales, donde la "teoría de la diferenciación social" juega un papel primordial.

En el presente trabajo abordaré algunas de las contribuciones que Pérez-Agote y otros sociólogos de la religión han realizado a la disciplina en relación a estos dos fenómenos y tres dimensiones. Tras realizar este ejercicio de síntesis, me focalizaré en el fenómeno del pluralismo religioso en su dimensión relacional, más concretamente, en su relación con la cultura, en una población cada vez más presente en nuestro país, las minorías socio-religiosas. 


\section{TEORÍAS DE LA SECULARIZACIÓN EN ESPAÑA}

Como he señalado, el programa de investigación de Pérez-Agote aborda dos de los fenómenos más relevantes y estudiados de la sociología de la religión contemporánea, el fenómeno de la secularización (Dimensión l y II) y el fenómeno del pluralismo religioso (Dimensión III). Empecemos por el primero.

Buena parte de los esfuerzos de los teóricos de la sociología de la religión contemporáneos consiste en delimitar qué significa y qué alcance (geográfico, temporal, poblacional, etc.) tienen las denominadas "teorías de la secularización", si éstas pueden ser mantenidas, deben ser reformuladas o abandonadas, así como desenmarañar cual es la relación entre los diferentes fenómenos que suelen identificarse como evidencias de que la secularización existe. Los trabajos del GERIRC sobre la religión en general y de Pérez-Agote en particular, pueden encuadrarse dentro de este complejo y multidimensional (Dobbelaere, 1981) concepto/paradigma. Las teorías de la secularización pueden, como propone Casanova, dar sentido y mayor potencia analítica desmenuzándolas en tres grandes interpretaciones o tesis, que a menudo tienden a diluirse y confundirse entre sí a la hora de formular e interpretar "La Teoria" (Casanova, 1994). Estas tres tesis, indudablemente, están interrelacionadas, pero pueden analizarse, en cierta medida, por separado. La originalidad de la propuesta de Casanova no descansa solo en distinguir diferentes teorías que suelen formularse como una sola, sino en cuestionar la necesaria secuencialidad y correlacionalidad de tales tesis. Estas tesis son:

1) La tendencia a nivel macrosocietal de la progresiva diferenciación, racionalización y especialización de las esferas societales (Política, Sociedad, Economía, Cultura, Derecho, etc.) propia de la modernidad occidental cristiana, fenómeno que conceptualizado desde diferentes perspectivas y autores ha ocupado desde, al menos, los clásicos trabajos de Durkheim y Weber, pasando por Parsons, Luhmann, Bourdieu o Habermas, un lugar preeminente en las reflexiones de la teoría sociológica europea. Dentro de estas reflexiones la religión ha jugado un papel central, ya sea por su pretendida naturaleza de "Dosel Sagrado" (Berger, 1967) o su alegado carácter "normativo-integrativo" durkheimniano. Todos estos autores, con heterogéneas perspectivas y raíces teóricas, prestan de una manera $u$ otra especial atención al concepto de diferenciación 
social. Dentro de los diferentes modos de entender estos procesos y teorías, Pérez-Agote se alinea con la tesis de la "diferenciación funcional de las esferas societales" (Pérez-Agote, 2012b: 32).

2) La tesis de la inexorable privatización y repliegue hacia la dimensión de lo privado de la religión (Luckmann, 1967), consistente con el trazo de una línea divisoria bipartita, propia del pensamiento modernista, entre la dimensión pública y privada.

3) La tercera, que Dobbelaere denomina "secularizacion individual" (2008), alude al declive de las creencias y las prácticas religiosas en las poblaciones y grupos. Ligados a esta tesis se han generado arduos debates sobre el carácter, cuando lo hay, de tal decrecimiento, y de si este debe de ser interpretado como una pérdida de religiosidad per se, o por el contrario, como una expresión no menos religiosas y no en decline, de una religiosidad sin institución (Iglesia) o desinstitucionalizada que deriva en un mantenimiento desarticulado de creencias sin identidad eclesiástica o un "creer sin pertenecer" (Davie, 1994) o incluso en creencias y prácticas individualizadas, propias de una labor de bricolaje (Hervieu-Léger, 2005).

En relación a la primera de las tesis - diferenciación funcional de las esferas societales-, Pérez-Agote aborda las relaciones entre dos esferas, política-religión, como espacio nodal donde se articulan la históricamente la privilegiada relación de la religión católica con respecto a las demás esferas (cultura, derecho, etc.) y analiza la progresiva separación y los sucesivos vaivenes de las relaciones de dichas esferas, que en España toma principalmente la forma Iglesia Católica-Estado. Pérez-Agote sitúa a España (Pérez-Agote, 2014) dentro de las características $y$ diferenciales pautas de secularización sureuropeas y católicas (Martin, 1978), caracterizadas por el vínculo orgánico de la institución eclesiástica con la esfera política, esto es, entre "Altar y Trono". Tal vínculo orgánico, que también podría denominarse como des-diferenciación de la esfera política con la religiosa, se presenta como uno de los marcos de referencia definidores de las identidades políticas en la historia española. El advenimiento de la modernidad vino a quebrar la armonía del matrimonio política-religión sellada en el antiguo Régimen, generando oposiciones binomiales progresismo-conservadurismo o modernidad-tradición, que se constituyeron como identidades centrales a la hora de ordenar las lealtades en el campo político. Buena parte de los procesos políticos que 
vendrían a constituir el campo político español y las incesantes luchas y guerras en los siglos XVII y XIX vendrían dados como resultados de las luchas de los diferentes actores para promover procesos de diferenciación entre política y religión o mantener la des-diferenciación presente. Los enfrentamientos entre las tentativas de las fuerzas modernizadoras para diferenciar ambas esferas, y el carácter reactivo de las fuerzas conservadoras para des-diferenciarlas, encontrarian su definitiva expresión en la II República y la consiguiente Guerra Civil, que constituiría el ejemplo más dramático de esta tensión histórica como fuerza motora de la historia política española.

En relación a la segunda de las tesis - privatización de la religión-, Pérez-Agote destaca la singular reubicación de la Iglesia como agente o cuasi-lobby político (Pérez-Agote, 2008) tras la transición a la democracia y la desaparición del Nacional-Catolicismo franquista. Singularidad que deviene, no de tal proceso de reubicación per se, sino del establecimiento de una Iglesia Católica con un perfil público y presencia mediático-política ${ }^{2}$ bastante más relevante y combativa, podríamos decir incluso beligerante, que en la mayoría de países católicos europeos (ver Dobbelaere y Pérez-Agote, 2015). En su papel de actor político en democracia, la Iglesia Católica ha orientado buena parte de su actividad política hacía la lucha y reivindicación de una redes-diferenciación o difuminación de los límites entre ética/lo público y moral/lo privado, ambas sujetas a una progresiva diferenciación (ej. aprobación de la Ley del Divorcio en 1981) tras los procesos de secularización sistémica entre Iglesia-Estado. Más concretamente, la Iglesia ha dirigido prioritariamente su labor político-institucional al respaldo de las resistencias conservadoras ante los cambios legislativos en materia bioética y familiar, como por ejemplo, en el caso del aborto (Pérez-Agote, Santiago y Montañés, 2015).

Sobre la tercera de las tesis de la "teoría de la secularización", esto es, decline de creencias y prácticas, Pérez-Agote encuadra a España dentro del "excepcionalismo europeo" a la vigorosidad de la religión en las conciencias y las prácticas en el mundo en general (Berger, 2001). En sus análisis Pérez-Agote distingue al menos tres oleadas de secularización

2 El espacio de lo político-mediático no es la única dimensión pública en la cual la Iglesia muestra una vigorosidad especial. El todavía extenso tejido asociativo católico y el papel comunitario de las parroquias, con la institución de Cáritas a la cabeza, también juegan un rol de gran relevancia, que cuestionan la idea de una "religión en lo privado". 
de las conciencias que han afectado a la sociedad española (PérezAgote, 2009). La primera en el siglo XIX y las dos siguientes a mediados y finales del siglo $X X$. Los rasgos más sobresalientes de estas dos últimas son la creciente indiferencia hacia el mundo de la religión en la segunda oleada (fijada alrededor de los 60 del pasado siglo con la incorporación de España a la economía de consumo) y la incipiente exculturación (Hervie-Léger, 2003) de las practicas católicas de la cultura, que afectan especialmente a los jóvenes tras la tercera oleada, que podría ubicarse en la siguiente generación y posteriores (Pérez-Agote, 2007). Los procesos de "exculturación católica", concepto popularizado por HervieLéger para el caso francés (2003), encuentran sus ejemplos más relevadores, quizás, en el declive de las prácticas rituales en su envoltorio católico, como bodas o funerales, y las nuevas formas de cohabitación, matrimonio y florecimiento de identidades sexualmente diversas (LGTB). El concepto de exculturación se torna especialmente relevante, además, porque nos remite de nuevo, cerrando el círculo, a la primera de las tesis, la diferenciación de esferas societales. En España parece que, siguiendo la clasificación de Casanova, la primera y la tercera tesis de la secularización se cumplen y correlacionan, aunque no por ello necesariamente la segunda. La religión católica parece estar empezando a perder todavía más importancia subjetiva para la población española tras su proceso de separación con la cultura, al menos entre la juventud. Quizás la excepción más relevante a esta separación cultura-religión la encontremos en el vigor de algunas creencias y prácticas propias del catolicismo popular en ciertas regiones del territorio todavía a día de hoy (Pérez-Agote y Santiago, 2005), como la devoción por las vírgenes, santos y/o asistencias a ritos propios, como romerias o procesiones, de alta religiosidad. Si bien tal relevancia y fervor radica en buena medida es su ligazón con la expresión de identidades y subculturas locales. Las relaciones cultura(s)-religión parecen entonces mostrar una gran relevancia para el devenir y el futuro de la religión católica en nuestro país.

Si pasamos a abordar el segundo de los fenómenos, el pluralismo religioso, que como hemos señalado constituyen el núcleo del presente artículo, se observa que este no es ni mucho menos un compartimento estanco separado del resto de fenómenos religiosos. Es más, los vínculos entre secularización y pluralismo religioso han suscitado relevantes debates en la disciplina sociológica, en especial por los intentos teóricos 
de Peter Berger en sus primeros trabajos por ligar y correlativizar ambos fenómenos como cara y envés del proceso de modernización occidental (Berger, 1967). Un proceso caracterizado, según Berger, por la urbanización, migración, ascensos en los niveles de formación y educación, expansión de los medios de comunicación y de transporte, etc., que obstaculizaban la posibilidad de imponer una visión monolítica y mono-céntrica sobre el mundo. En España, al menos, el vínculo entre ambas sí parece presentar cierta consistencia, ya que la desarticulación del régimen nacional-católico franquista y la consiguiente desdiferenciación entre esferas política-religión ${ }^{3}$ y derecho-religión, sin duda habilitó y promovió la diversidad religiosa en España. El florecimiento del pluralismo religioso en España tuvo y ha tenido que ver ciertamente con tales procesos desreguladores y promotores de la libertad de expresión religiosa, pero encuentra en otro proceso el motivo de su exponencial expansión actual.

\section{El "NUEVO PLURALISMO RELIGIOSO" EN ESPAÑA EN EL SIGLO XXI}

Los trabajos de Pérez-Agote y el GERIRC han prestado mayor atención a la secularización que al pluralismo. De hecho, los trabajos sobre esta última cuestión, aún siendo significativos, son menos numerosos y más limitados en cuanto a su alcance. Entre estos, destaca el trabajo de indole cuantitativa realizado por Pérez-Agote y Santiago en colaboración con el CIS (2009) que se suma a la encuesta general sobre la religiosidad de la población española que estos mismos autores realizaron también con ese organismo en 2005. La encuesta sobre el pluralismo religioso de Pérez-Agote y Santiago ofrece, a día de hoy, una de las pocas panorámicas sobre las que delinear diferentes actitudes, opiniones y creencias de las poblaciones religiosamente diversas, atendiendo en especial al caso de los musulmanes y protestantes evangélicos, que fueron el grupo target principal de la metodología, con base en los centros de culto.

La atención prestada al fenómeno del pluralismo religioso por parte del sociólogo vasco tiene origen en la reciente e intensa llegada de inmigración trasnacional que ha vigorizado y acentuado el proceso de

3 Para evitar caer en relatos modernistas o teleológicos conviene recordar que los procesos de diferencación-desdiferenciación son históricos, contingentes, graduales, por ello difícilmente absolutos, y siempre potencialmente, tanto en uno como en otro polo, reversibles. 
diversidad religiosa en España y que lo ha convertido en uno de los fenómenos sociológicos y de cambio social más relevante de los últimos tiempos. La España histórica y culturalmente católica nunca ha sido del todo ajena al fenómeno del pluralismo religioso nacional, y ni mucho menos todo pluralismo religioso actual es de origen foráneo, pero desde fechas recientes, alrededor de comienzos del siglo $\mathrm{XXI}$, asistimos a un fenómeno cuantitativa y cualitativamente diferencial: la aparición de un pluralismo religioso de base no nacional, corpulento, visible y pujante, que por ello el autor denomina "nuevo". Estas grandes corrientes migratorias han Ilegado a España principalmente de Latinoamérica, del Norte de África y el África-Subsahariana y, tras la ampliación de la UE en 2007, de los países del este europeo, en especial, aunque no solo, de Rumanía. Las tres grandes religiones de la nueva población inmigrante son el Cristianismo Ortodoxo, el Cristianismo Protestante Evangélico, especialmente Pentecostal ${ }^{4}$, y el Islam. El Islam, en especial en su versión Suní, se ha extendido en territorio español a través de las corrientes migratorias provenientes sobre todo de África. Entre estas, sobresale la población magrebí, en especial marroquí, y en menor medida otras poblaciones del África Occidental, como la senegalesa. En cambio, el evangelismo pentecostal ha desembarcado transnacionalmente en España, en buena medida, tras la reciente recepción de población latinoamericana. Una región, la latinoamericana, que ha sido sacudida por intensos, aunque heterogéneos en cuanto a alcance en los distintos países y subregiones, procesos de conversión al evangelismo en el último cuarto del siglo XX (Stoll, 1990). Algunos de los migrantes eran ya conversos en su región de origen, otros se han convertido en territorio español, aunque lo relevante es que en líneas generales, observamos una diferencial incidencia y expresión, en comparación con la población española, de la religión evangélica pentecostal entre tales poblaciones. Si bien, las diferencias entre países y subregiones es extremadamente diversa (Martin, 1990). Una diversidad que seguramente incluye todavía

\footnotetext{
4 Por sus conocidas y populares estrategias evangelizadoras en los espacios públicos, que incluyen desde abordar a transeúntes por las calles hasta incluso acudir a las puertas de los domicilios de forma sistemática, el evangelismo y/o las religiones milenaristas, como por ejemplo los Testigos de Jehová, muestran una visibilidad social que a menudo sobre representa su robustez numérica en los imaginarios colectivos de la población española. No obstante, el evangelismo es ciertamente ya robusto en España y es extremadamente diverso en cuanto a composición como muestra la existencia de metodistas, bautistas, pentecostales, Iglesias independientes, etc. Entre tal diversidad, el pentecostalismo es la rama evangélica más extendida en España.
} 
mayor complejidad si lo analizamos en relación a otros factores como el género, la generación 0 incluso el estatus socioeconómico. El evangelismo pentecostal también muestra un especial vigor entre poblaciones subsaharianas y del África occidental, como por ejemplo, la población de origen nigeriano y ghanés.

El Islam, el Evangelismo y el Cristianismo Ortodoxo no agotan el pluralismo y la diversidad religiosa en España (Judaísmo, Budismo, Testigos de Jehová, Hinduismo, los Hare Krisna, Confucianismo, Taoísmo, y un largo etcétera), pero en la actualidad estas tres religiones constituyen sin duda los canales más robustos de expansión numérica de la pluralidad religiosa en el territorio. Dentro de estas tres grandes religiones, el Islam y el Evangelismo configuran y dan forma, por su incidencia, visibilidad, vigorosidad, impacto e influencia, el mapa religioso plural de nuestro país, puesto que los Ortodoxos, en su mayoría proveniente de países ex-comunistas han sufrido su propio y particular proceso de secularización estatalmente orientado (Martin, 1978). Aunque muchos ciudadanos provenientes del este europeo tiendan a mantener su identidad religiosa ortodoxa nominal, la vitalidad, visibilidad y vigor de la Iglesia Ortodoxa es débil en comparación con el auge del Evangelismo $o$ el Islam. El mapa de las grandes transformaciones en el campo religioso español se completa con la masiva y acelerada conversión de una buena parte de la población gitana nacional al evangelismo pentecostal (Cantón Delgado et al., 2004) desde los años 70 del pasado siglo, promovida, alentada y estimulada, especialmente aunque no solo, por la Iglesia Étnica Gitana conocida como "Iglesia Evangélica de Filadelfia".

La condición religiosa plural en España no está inherentemente e indisolublemente unida a la condición migratoria ni a la diversidad étnica. En las religiones a analizar (Islam y Evangelismo) existen y nos encontramos con conversos sin condición migratoria o pertenecientes a grupos étnicos minoritarios. Por ejemplo, existe un histórico núcleo importante de conversos nacionales al Islam en regiones como Andalucía, así como familias y población evangélica de origen nacional dispersa por todo el territorio. Pero un fenómeno es evidente. Buena parte de la población que muestra una condición religiosa plural muestra asimismo una condición étnica o nacional diferencial. La suma de ambos fenómenos da lugar a otro de gran novedad: la intersección de los ejes étnico/migratorio y religión como espacios donde se 
constituyen nuevas minorías sociales, o minorías dentro de minorías. Pertenecen a estas identidades doblemente minoritarias, entre otras, poblaciones tan diversas como musulmanes subsaharianos $y$ norteafricanos, latinoamericanos (con toda su diversidad de identidades nacionales) evangélicos pentecostales, gitanos evangélicos pentecostales, etc.

En relación a las creencias y prácticas, nos encontramos con que buena parte de los grupos más numerosos que conforman la inmigración española, como por ejemplo latinoamericanos, norteafricanos o subsaharianos, muestran, en líneas generales, un menor nivel de secularización individual (más prácticas y mas creencias de índole religioso) que la población española y, en muchas ocasiones, identidades y religiones no católicas (Pérez-Agote y Santiago, 2009: 30).

Si nos movemos desde el plano de la migración hacía el de la identidad religiosa, observamos que aquellos que tiene una identidad evangélica y musulmana en España, son más practicantes y asisten con mayor asiduidad a los cultos y centros religiosos que sus homólogos católicos y, además, otorgan una mayor importancia subjetiva a la religión en sus vidas (Pérez-Agote y Santiago, 2009). Podría argumentarse aquí que el factor explicativo de estas diferencias radica en el origen foráneo de la gran parte de aquellos que muestran identidades no católicas, si bien, parte de nuestra población nacional, como los gitanos, en donde la religión tiene un especial vigor, muestra una tendencia similar. Es posible, pues, que no solo el carácter nacional diverso sino también, y muy especialmente, las fronteras sociales, étnicas, culturales, etc., sean unos de los factores más relevantes (Bruce, 1996) que obstaculizan la irradiación social de la tendencia a la secularización individual en España.

En relación al papel público ${ }^{5}$ de los centros religiosos, Pérez-Agote señala que estos multiplican sus funciones (Pérez-Agote y Santiago, 2009) en situación de minoría, ocupando un lugar central en los mecanismos de integración y solidaridad de las mismas.

En relación a los procesos de diferenciación de esferas societales entre minoría sociales, unas de las esferas prioritarias que emerge como destinataria del análisis no puede ser otra, por la especial relevancia de ambas en la vida social, que la relación entre cultura y religión. Las

5 Para consultar el papel político de las asociaciones inter-fe e inter-religiosas, véase Griera para el caso catalán (2012) y Lamine para el caso francés (2014). 
relaciones entre ambos elementos, insistimos, son marcada e históricamente contingentes. Previamente, en el análisis de la población española, subrayamos la relevancia del concepto de exculturación para entender los incipientes y contemporáneos procesos que separan la cultura y la religión en sociedades europeas históricamente católicas. En el caso del pluralismo religioso, también hemos visto que las fronteras entre poblaciones mayoritarias y minoritarias, y entre ellas las culturales/étnicas, pueden jugar un papel relevante a la hora de obstaculizar procesos de irradiación secular. La pregunta a formularse es: ¿cómo abordar un análisis que incluya la relación entre la esfera cultural y religiosa en poblaciones doblemente minoritarias?

\section{INTERACCIONES ENTRE CULTURA Y RELIGIÓN EN MINORÍAS SOCIO- RELIGIOSAS. DIFERENCIACIÓN/DESDIFERENCIACIÓN DE ESFERAS}

Una de las ideas que subyace bajo las perspectivas teóricas que ponen el acento en la tesis de la diferenciación social al abordar el fenómeno religioso es la siguiente: cuanto más entrelazados, entretejidos y enredados (o des-diferenciados en lenguaje de la teoría) se encuentre la religión con otras esferas, como la política, el derecho, o la cultura, mayor será su vigorosidad en las identidades, representaciones colectivas, vida social y subjetividad de los individuos. Y, por ende, más difícil será su desaparición. La ligazón entre religión-cultura, en principio, sería una de las dimensiones clave para el mantenimiento de la relevancia subjetiva de la religión en la vida diaria y las biografías de las poblaciones, grupos y comunidades.

Parte de la literatura que estudia los vínculos entre cultura y religión entre minorías sociales lo hace en términos fronterizos, analizando como ambos universos simbólicos se interrelacionan y disuelven en proyectos de supervivencias étnicas. Ejemplos de este fenómeno son las conocidas como etnoreligiones, cuyos representantes más conocidos son, quizás, los grupos etnoreligiosos Judio y Amish. En ambos casos la religión se disuelve en etnicidad o frontera entre grupos. Aquí tomaremos una óptica distinta, abordaremos las relaciones entre cultura y religión en procesos donde la supervivencia de una etnicidad o grupalidad fronteriza no presupone el necesario solapamiento entre identidad, cultura y religión. Aquí es importante no confundir un relativamente bajo grado de diferenciación entre cultura y religión en una población religiosa dada con una etnoreligión. El peyorativo, 
coloquial y históricamente arraigado en España concepto de "moro" para los musulmanes, por ejemplo, tiende a aunar en un todo difuso y opositivo (el no cristiano por excelencia) de carácter racial, cultural, histórico y religioso a toda una categoría de personas que son homogeneizadas y etnificadas con relación a tal apelativo. La vigencia de tal concepto nos da pistas sobre que la religión puede formar parte esencial de la etnicidad, pero, y aquí viene lo relevante para distinguir el Islam de una etnoreligión, la etnicidad no queda delineada exclusivamente con relación a la religión. Ambas categorías no se disuelven una en la otra. Ni todo musulmán se enfrenta a la categorización de "moro", ni toda persona categorizada con ese calificativo tiene incluso porqué identificarse como musulmana. Asimismo, se hace vital no confundir religiones intensamente híbridas con la cultura y la identidad, como el evangelismo pentecostal gitano promovido por la Iglesia Evangélica de Filadelfia, con una religión étnica. Aquí, pese a que se hipotetiza con relatos de "elección" e identidades de "pueblo elegido por Dios", tales construcciones se insertan en las narrativas de salvación universalistas propias del Cristianismo. No todos los gitanos serán salvados, pero todo cristiano no gitano lo será.

Para entender mejor las relaciones entre cultura y religión en los grupos a analizar, debemos prestar atención a las diferentes estrategias de reproducción de la religión evangélica pentecostal e islámica. El Cristianismo y el Islam son, ambas, religiones de salvación universal y por ello, conversionistas. En principio, todo aquel que sienta la llamada divina puede convertirse al Cristianismo, y pasar a formar parte de los bautizados en Cristo, o al Islam, declarando (en la tradición Suní) la profesión de Fe Islámica o "Shahada" y pasar a formar parte de la Umma, la comunidad de creyentes musulmanes. Pero que ambas sean religiones conversionistas no implica que sus principios de reproducción social sean idénticos. El evangelismo, rama cristiana nacida en plena modernidad Occidental, asume en su formulación la diferenciación de esferas societales propio de tal estadio histórico y región geográficacultural, reproduciéndose esencialmente por una evangelización de tipo individual (new-born). El evangelismo asume su posición minoritaria para desde la misma, conquistar el campo religioso. El Islam, en cambio, ha tendido históricamente a reproducirse en un todo in o desdiferenciado donde cultura, religión, identidad, política, derecho, sistema educativo pasan a ser parte de un entramado único que permite 
la reproducción religiosa mediante la propia reproducción societal. Esto no quiere decir que todas las poblaciones islámicas sean transhistóricamente similares, o que el Islam sea igual asimismo trasnacionalmente, sino que este tiende a reproducirse de tal manera, con su amplia variedad de diferencias nacionales y regionales, en las sociedades en donde es la religión oficial y hegemónica. Ahora bien, en situación de minoría social, el Islam ya no puede reproducirse societalmente. $y$ es en tales situaciones cuando este toma posiciones defensivas y trata de replegarse y permanecer alineado con la identidad y la cultura de los diferentes grupos para sobrevivir en entornos adversos.

En relación a la cultura, pues, ambas religiones juegan con principios antagónicos. En el evangelismo, la religión y la(s) cultura(s) quedan diferenciadas de raíz y por ello, sobre todo para el éxito de la primera, tales relaciones necesitan de un re-acoplamiento, en especial cuando el evangelismo trata de extenderse por poblaciones con etnicidades vigorosas. En las sociedades donde el Islam es una religión nacional, la religión y la(s) cultura(s) tienden, si bien heterogéneamente, a formar parte de un mismo entramado. Por ello, lo relevante en las interacciones religión-cultura en el Islam radica en el fenómeno opuesto: los procesos de diferenciación y potencial re-desdiferenciacion entre ambas esferas derivados de la experiencia migratoria y la socialización de las nuevas generaciones en entornos en donde el Islam no es una religión nacional.

\subsection{El caso de los musulmanes del Magreb, en especial Marruecos, con experiencia individual o familiar migratoria}

El asociar identidad cultural y religiosa entre ciertos inmigrantes, como por ejemplo, tildar a alguien de musulmán-marroquí supone, en muchas ocasiones, un pleonasmo. En algunas sociedades islámicas hay un estado bastante desdiferenciado entre cultura y religión, y en algunos casos, como el de algunas de las primeras generaciones de migrantes en España, es difícil separar identidad, cultura y religión. El grado de diferenciación entre cultura-religión varía en las poblaciones, y también existen minorías religiosas no musulmanas en la zona del Magreb, como Cristianos o Hindués, pero es evidente que: primero, la cultura en las sociedades islámicas del Magreb es, en buena medida, cultura islámica; y segundo, el grado de diferenciación entre cultura y religión en tales sociedades, pondremos de nuevo el caso marroqui de ejemplo, es más 
bajo que en las sociedades católicas, al menos que en las europeas occidentales.

Uno de los ejemplos más claro de este fenómeno radica en el orden de las prácticas y de sus interpretaciones simbólicas, el orden por excelencia donde se manifiestan las representaciones del nosotros y el mundo. Pongamos el ejemplo del velo o "Hiyab" y las recientes polémicas suscitadas en Francia. Como señalan Pérez-Agote y Santiago:
"Allí donde este proceso [de diferenciación] alcanza un nivel alto cada esfera despliega sus propios símbolos; mientras que allí donde la diferenciación no es tan fuerte los símbolos tendrán un significado más polivalente, al no darse fronteras claras entre las esferas. Y así, el significado del velo es, para un autóctono, religioso, mientras que para un musulmán, por ejemplo, sobrepasara la esfera religiosa y será también cultural, político, identitario, familiar, etc." (Pérez- Agote y Santiago, 2009: 75).

Pero señalar que las esferas culturales y religiosas tienden a presentar un alto grado de solapamiento y que la cultura islámica impregna el campo cultural de las poblaciones musulmanas del Magreb, tampoco conlleva a la homogeneización cultural de tales poblaciones. La población musulmana magrebí es diversa. Y no solo por su origen nacional. Por ejemplo, los entornos originarios desde donde se producen las migraciones son un factor importante para determinar el carácter diferencial de la expresión cultural (Torres et al., 2007). Existen grandes diferencias entre la población musulmana provenientes de entornos rurales y urbanos (entre otras, en el grado de conservadurismo cultural). Asimismo, entre los marroquies, por ejemplo, existen grandes diferencias según su etnicidad y origen, beréber o árabe. Tal diversidad se refleja en muchas ocasiones en la asistencia a las mezquitas. Si bien es cierto que en ocasiones estas agrupan en sus prácticas a poblaciones con diferentes backgrounds debido a que la religión islámica tiende a homogeneizar algunos rasgos culturales transnacionalmente, no en pocas ocasiones las líneas divisorias se reproducen también en las mezquitas, generando asistencias diversificadas por factores como la nacionalidad, la región de origen o la etnicidad. No obstante, un fenómeno es común a prácticamente todos los inmigrantes con identidad religiosa musulmana. Los procesos de diferenciación entre cultura y religión tienden a complejizarse en mayor medida en la segunda generación de inmigrantes y posteriores que en la primera. En 
el caso español, en el interior de los universos simbólicos de los nacionales españoles de origen familiar musulmán, ya más españolizados, las relaciones entre identidad, religión y cultura distan de ser necesarias. Las rupturas se suceden y "las lógicas de las cosas", al contrario de muchos de sus progenitores, no pasan por tal unidad, por lo que suelen sucederse progresivas disociaciones entre cultura y religión. En este caso, cuando la des-diferenciación no es todavía intensa la cultura encuentra la religión como aliada en la diferencia y se ayuda de esta para sobrevivir en entornos desfavorables, y la religión, a través de sus instituciones, principalmente las mezquitas, actúa asimismo como promotor de la cultura. Aquí las mezquitas juegan aqui un papel esencial, tanto en la integración social de las minorías, como mediante todo tipo de actividades religiosas, de ocio y formación, dirigidas a la reproducción de la identidad y la cultura originaria, especialmente la lengua.

"Los centros religiosos son centros de integración social (...)
estos centros no son el único mecanismo de re-producción de
la identidad original, pero si uno muy importante; y
constituyen, sin duda ninguna un medio poderoso de
integración social. La integración de una persona pasa, al
menos en parte, por su participación en mecanismos de
integración colectivas, como estas identidades religiosas"
(Pérez- Agote, 2012b: 41).

La mayor parte de la inmigración musulmana en España es aún muy reciente y no tenemos todavía demasiados ejemplos del impacto en segundas y posteriores generaciones. En ocasiones, la religión podrá perder influencia en la vida de los individuos e iniciar su separación de la cultura, ya más "españolizada". A medida que pasan las generaciones y las vivencias en entornos de la sociedad de acogida de los progenitores, la cultura puede, por tanto, disociarse de la cultura nacional de origen y, por ende, de la religión. Asistimos al fenómeno de las identidades y experiencias vitales híbridas, con la emergencia de jóvenes que no pueden sino practicar dobles pertenencias y que "viven entre dos mundos" marcadamente diferenciales. Dos mundos, además, en los que se demanda el cumplimiento de una serie de roles y valores determinados, en algunas ocasiones incluso contradictorios. Las nuevas generaciones de musulmanes españoles con origen familiar migratorio se encuentran a caballo entre unos lazos familiares y de parentesco que representan la cultura de origen y una socialización, marcada especialmente por la escuela y los grupos de pares, que representan la 
nueva cultura. Aquí, la religión puede todavía pervivir, pero en ocasiones se promoverán nuevas y alternativas identidades musulmanas (Jacobson, 1997), que tenderán asimismo a vincularse a las culturas y la lengua (el español) nacionales de las nuevas sociedades. Asistimos, con ello, al nacimiento de un Islam reformulado y vinculado con la sociedad de acogida, esto es, un Islam con base española, o Islam Español.

De igual manera, también puede aparecer un fenómeno singular, la enérgica vuelta de las nuevas generaciones a la cultura originaria, esto es, a la re-desdiferenciación entre cultura y religión. Una vuelta a lo tradicional que, con el paso de las generaciones, puede que incluso se exprese con mayor vehemencia que en la que se expresaba en sus progenitores. Esto será así, en especial, si la religión pasa a ser un factor de diferenciación y estigmatización social en las sociedades de cristianismo hegemónico. Aquí, ya sea mediante un proceso de desdiferenciación o una vuelta a las tradiciones culturales del país familiar de origen, o de re-significación, con una reformulación de la religión en nuevos entornos, el simbolismo que aúna lo religioso y lo cultural sigue siendo central. Continuemos con el mismo ejemplo aludido con anterioridad, el uso del "Hiyab" por parte de las mujeres musulmanas. Dicho uso puede entenderse desde una doble perspectiva. Desde el punto de vista intrareligioso, esto es, cuando el destinatario del símbolo es la propia comunidad musulmana, el significante da lugar a una matriz de significados fácilmente de-codificables por los individuos de origen musulmán. Es un signo, entre otros, de virtud moral, decencia, castidad sexual y adscripción a una serie de valores relevantes para la población religiosa y culturalmente musulmana. En la mayoría de ocasiones es un símbolo naturalizado que forma en tal medida parte del acervo cultural cuyo uso no implica ninguna intención subjetiva por parte del portador. Desde un punto de vista externo, el de las relaciones interreligiosas e interculturales, el símbolo puede pasar a ser político, ya que lo que en principio es un significante que da lugar a significados de-codificables por la audiencia religiosa musulmana, pasa a ser asimismo fuente de estigmatización y diferencia respecto a una mayoría que queda fuera de los códigos religiosos musulmanes y que tiende además a rechazarlos y condenarlos en una actitud de sospecha y recelo. Así, por ejemplo, una mujer cuyos padres no son especialmente religiosos o devotos de la religión islámica puede encontrar en las sociedades de histórica mayoría 
cristianas en el "hiyab" un factor identitario y/o político con el que reivindicar su identidad y el derecho a la diferencia cultural y religiosa.

La religión, por tanto, puede cobrar una creciente importancia identitaria y subjetiva con el paso de las generaciones si en el entorno en donde las atribuciones de identidad fronterizas se produce un descrédito y una condena de las poblaciones religiosa y culturalmente diversas. Una afirmación, pues, puede darse por cierta en el caso musulmán para las sociedades hegemónicamente cristianas, en donde el Islam es el denostado "Otro religioso" por excelencia. El grado de permanencia o vuelta a la religión y cultura originaria y/o las resignificaciones políticas de los símbolos musulmanes tendrá mucha relación con las oportunidades de integración que ofrezca la sociedad donde las convivencias tienen lugar. Las "identidades reactivas", como denomina Álvarez-Benavides (2013) a las identidades que se vuelven sobre sí en el caso marroquí en Madrid son el envés de la "Islamofobia" y aparecen cuando las fronteras sociales se tensan y/o las oportunidades de acceso a los bienes valorados socialmente (véase mercado laboral, educación, integración social, estatus, etc.) se obstaculizan.

\subsection{El caso de los evangélicos pentecostales con identidad étnica nacional diversa (gitanos) o latinoamericanos con experiencia individual/familiar migratoria.}

La religión evangélica pentecostal, como todo cristianismo, es una religión de salvación universal, caracterizada por una fuerte labor evangelizadora. En sus proyectos de expansión, el Catolicismo y el Islam han utilizado el proselitismo como herramienta en sus inicios, pero este no es su mecanismo de reproducción principal. Ambas religiones, tras alcanzar su hegemonía en el campo religioso, tienden a reproducirse por su alineación con otras esferas societales, especialmente las élites políticas, el sistema educativo y la cultura nacional, y su reproducción suele producirse como un todo con el resto de ámbitos societales. El Evangelismo, en cambio, acompasado y nacido en plena modernidad occidental, está diseñado y pensado para reproducirse sin aludir a una imbricación orgánica con el resto de esferas, una vez estas han quedado desarticuladas y diferenciadas en los macro-procesos sociales propios de las sociedades modernas occidentales. El evangelismo se reproduce autónomamente por conversionismos individuales, con lo que todo el peso de la reproducción recae en los propios religiosos y su tarea 
evangelizadora. Ninguno de tales mecanismos de reproducción es más efectivo per se, sino que son maneras diferenciales de llegar a un objetivo común: erigirse en hegemónico en el mercado religioso Así, es posible que los diferentes evangelismos puedan llegar en algún momento a constituirse como religión mayoritaria en ciertos territorios geográficos y países, como por ejemplo, en Guatemala (Cantón Delgado, 1998).

Todas las religiones monoteístas de raíz abrahámica, como el Judaísmo, el Cristianismo o el Islam, son religiones éticas, cuyo fin último es orientar el comportamiento moral del hombre en el mundo. El Islam y el Catolicismo lo consiguen indiferenciándose de la cultura y el "mundo". El evangelismo lo hace, por contraposición, "separándose del mundo", reivindicando desde ese no lugar 0 , mejor, el lugar que se perdió en la modernidad secular. En definitiva, apostando por una vuelta a los orígenes y la puridad, donde la religión recupere su lugar hegemónico para dictar los destinos del Hombre. Y es aquí donde la religión ya no puede ser rutina y norma, categorias que apelan a la potencialidad inscrita de un incumplimiento humano sino a algo hiperactivo $e$ hiperpresente, capaz de re-totalizar de nuevo la des-totalizada secular experiencia humana y dictar los pasos de la humanidad. El evangelismo, por ende, y como no dejan de subrayar los evangélicos, es la religión del "Dios Vivo", que interviene, actúa e intercede con la ayuda del Espíritu Santo en las vida cotidiana del creyente. El catolicismo, por ejemplo, sería, para los evangélicos, la expresión por antonomasia de la letra muerta, de un Dios que no vive y no desata de manera sobrenatural y recurrente bendiciones en las vidas cotidianas de sus adoradores. El binomio doctrinal vida/muerte propio de la lógica evangélica es una conceptualización que transfiguradamente trata de captar no solo cuanto de relevante es la religión en la vida cotidiana de un individuo, sino cuales son las expectativas de tales creyentes en relación al poder de la religión para mejorar la vida de estos.

La rama pentecostal del evangelismo es la más exitosa de todas ellas a nivel global (Barrett y Johnson, 2004), tras su reciente nacimiento a finales del siglo XIX es conocida como "la religión del Espíritu Santo" (Hollenwenger, 1972). El Espíritu Santo, la tercera persona de la Trinidad, es el sujeto más etéreo, inmaterial, abstracto e incontenible del Cristianismo. Un espíritu aparece, y desaparece, "se mueve" por doquier, bendiciendo a todo aquel que esté abierto a la influencia de este en su 
vida, o como les gusta señalar: "el Señor es un caballero, llama a la puerta pero no entra sin ser aceptado". La expansión del evangelismo pentecostal no puede anclarse en ningún particularismo geográfico o cultural determinado, ya que este sería un lastre que condenaría e imposibilitaría el impacto evangelizador de una religión que se reproduce por conversionismos individuales. El evangelismo no puede sino partir de una diferenciación de las relaciones necesarias entre religión y cultura, al menos como se expresan en las sociedades no secularizadas donde las religiones de libro de origen pre-moderno como el Catolicismo o el Islam son hegemónicas. No obstante, la religión, por muy abstracta y etérea que se nos presente, a menudo necesitará en algún grado de la cultura para materializarse y reproducirse con éxito, en especial y sobre todo cuando los evangelizados son minorías con identidades sociales y culturales diferenciales. Asimismo, cuando tras procesos generacionales de reproducción, o en otras palabras, tras sucederse las generaciones que nacen con el evangelismo como religión de referencia, la religión se desplaza desde su posición sectaria, en los márgenes del campo religioso legítimo, a convertirse en una "denominación religiosa", las relaciones cultura-religión también pueden quedar alteradas.

En todo caso, los diferentes juegos de hibridación entre cultura y religión son desiguales y diferenciales. Existen grupos que se apropian culturalmente de las religiones en mayor medida que otros. Dentro de los grupos, asimismo, los miembros se apropian diferencialmente de la religión y existen diferentes juegos de hibridación con la cultura.

Las religiones evangélicas forma parte del denominado "renacimiento comunitario" de las religiones en la modernidad occidental. Como señalan Berger y Luckmann en su popular trabajo "La construcción social de la realidad" (1968): "los procesos de conversión implican una transformación radical de la realidad subjetiva que no pueden ser sino proceso de una re-socializacion que demanda una estructura de plausibilidad objetiva, esto es, la "Comunidad Religiosa" (Ibid.: 197). Como he señalado, el Cristianismo Evangélico por contraposición, por ejemplo, al Islam o al Catolicismo no tiende a hibridar identidad socialcultura-religión sino que, dado que demanda un contacto y una experiencia directa con Dios, tiende a genera más bien una vinculación individuo-religión. Por tanto, aquí la religión tiende a envolverse comunitaria, emotiva y culturalmente a través de la congregación de 
comunidades étnica o culturalmente homogéneas y la apropiación de sus gramáticas, expresiones culturales y símbolos, para hacer factible la conversión y potenciar la evangelización "a toda cultura, tierra y nación". Es común escuchar, por parte de aquellos religiosos que no atienden o han dejado de atender a los centros religiosos por esa razón, que tal o cual Iglesia evangélica pentecostal está "demasiado culturizadas", que los contextos rituales, los ambientes, la música, la doctrina, la forma de abordar las problemáticas o las actitudes de tales grupos están influenciadas de arriba a abajo por la cultura de los mismos. Las Iglesias aquí, pasan a ser Iglesia etnificada o capitalizada por individuos con el mismo origen nacional. Es el fenómeno de las "Iglesias Étnicas" o "de origen nacional". Y es precisamente ese carácter culturalizado de la religión que funciona como principio de inclusión-exclusión, sea cual sea la cultura o subcultura nacional o étnica analizada, el que habilita la asistencia constante a los "cultos" y "centros religiosos" del grueso de tales grupos. Asistencias regulares que, en clave durkheimiana, funcionan como principio motor y reproductor del nuevo $y$ extremadamente exigente, en términos de moralidad, prácticas, códigos, interpretaciones y representaciones del mundo, universo simbólico evangélico pentecostal. Uno de los elementos clave en tal hibridación cultura-religión es el carácter asimismo étnico, nacional o subregional, de los pastores. El evangelismo pentecostal como religión de raíz protestante, fomenta la independencia de las congregaciones locales y la descentralización de las estructuras organizativas y de autoridad religiosa. El Pentecostalismo es un hito histórico dentro del Protestantismo en general y el Evangelismo en particular, porque es la expresión de este que más fomenta los liderazgos locales o intraétnicos. El producir mensajes apropiables demanda una destreza y competencia comunicativa en los códigos, modos de expresión y lenguajes de la audiencia realizando un ejercicio de acercamiento a las particularidades y singularidades culturales de las comunidades a evangelizar. Por ello es usual que el liderazgo en el ámbito religioso en las Iglesias Evangélicas pentecostales pase a recaer sobre líderes locales y miembros de las minorías étnica o migrante que inician un proceso masivo de conversión. No obstante, los liderazgos son un espacio relevante pero no el fundamental donde se juegan los procesos de re-creación del pentecostalismo y su hibridación con las cultura. Los procesos de recreación colectiva del pentecostalismo son, en esencia, promovidos por las propias comunidades que participan en su reproducción. La 
flexibilidad doctrinal y litúrgica permite a los creyentes la incorporación de esquemas, marcos y significados culturales que fomentan la incorporación de sentidos, herencias, experiencias y contextos culturales específicos y singulares propios de comunidades en su vida cotidiana. El argumento que deseo subrayar aquí no es que la religión, usando como plataforma los centro religiosos, promueva "cultura", sino que más bien, la religión se nutre aquí de la cultura para sus propios fines.

Ahora bien, es importante subrayar que el pentecostalismo no se nutre exclusivamente de la diferencia cultural para su supervivencia entre las minorías sociales. El Pentecostalismo, no tiene, ni aún en condición de minoría, porqué extenderse y recrearse bajo parámetros étnicos y/o nacionales diferenciales. Es más, son muchos los procesos registrados de aculturación por parte de los religiosos evangélicos-pentecostales en situación de minoría social en otras latitudes y contextos, como, por ejemplo, la de algunos miembros de poblaciones indígenas en América Latina en periodos de urbanización y éxodo rural. Muchos de estos desplazamientos 0 incluso passing interétnicos parecen estar relacionados, aunque no solo, con las vertientes pentecostales de corte neocalvinista, hiperindividualista y orientados hacía el éxito económico de inspiración estadounidense, como por ejemplo las diversas "Iglesias de la Teología de la Prosperidad" que forman una parte importante del entramado del movimiento pentecostal. Tales pentecostalismos de corte neocalvinista han llegado a España, pero su impacto entre las minorías en líneas generales no parece por ahora ser tan fuerte como el del pentecostalismo más "comunitario-cultural". Estos pentecostalismos de corte neocalvinista han impactado de forma desigual a las minorías de nuestra población religiosa, y seguro más en comunidades migrantes que entre la población gitana, en este último caso por tensiones obvias con los valores familiares propios de la(s) cultura(s) gitana(s). No obstante, esta diversidad nos pone en sobre aviso de la plasticidad de la religión pentecostal y su capacidad para recrearse a sí misma en diferentes contextos y con diferentes estrategias en relación a la cultura. Así que, sin ánimo de sesgar la plasticidad pentecostal y la variedad de contextos de las poblaciones religiosas, podemos decir que en situación de minoría social la(s) cultura(s) y la religión pentecostal tienden a hibridarse, aunque existen otros itinerarios de interacción. En este primer itinerario "comunitario- 
cultural", la religión evangélica pentecostal no rompe ni refuerza identidades étnicas/nacionales sino que tiende a in-corporar(las). La religión evangélica habilita la generación de nuevos ejes sobre las que articular las identidades culturales, étnicas o nacionales, esto es, el surgimiento de pluridentidades. La identidad sacra no tiene porque derivar en un abandono de la identidad profana. En los casos en los que identidad diferencial tiende a formar parte intrínseca y primordial del ser en el mundo y genera una extendida etnicidad de resistencia, como en el caso de muchos gitanos, la religión actúa como un reformulación de tales identidades. Aquí el evangelismo pentecostal ofrece nuevos ligámenes religioso-culturales sobre las que reconfigurar la "gitaneidad" y la pertenencia al grupo étnico, sin perder en el proceso ni un ápice identitario gitano.

No obstante, si como se ha señalado, buena parte del progresivo éxito de la religión pentecostal en España deviene de su capacidad para incorporar e hibridar la diferencia cultural en el evangelio y dar expresión en el campo religioso del yo cultural, no todas las Iglesias pentecostales y/o centros religiosos en España son étnica, cultural o nacionalmente homogéneos. Entre los latinoamericanos, por ejemplo, los ejes son esencialmente dobles. En algunos, la asistencia a los centros religiosos se articula sobre la identidad nacional, en otros, en cambio, la composición de los cultos es plurinacional, hispanoparlante y con población de origen o con relación familiar con cualquier de los territorios latinoamericanos. La identidad y la asistencia a las Iglesias rara vez se llega a articular, sin embargo, sobre la identidad latina, constructo que solo tiene sentido en cuanto existe otro mayoritario "el español" que las categoriza y homogeniza de tal manera. Para muchos latinoamericanos, la llegada a España supone de hecho la primera toma de consciencia de que existe una categoría de identificación socialmente relevante ligado a lo latino. En este último caso, la identidad latina, que en los países de origen era una identidad difusa y más geográfica que subjetivamente significativa, empieza a cobrar cierta relevancia como categoría que genera diferencias sociales para con el Otro español. No obstante, esta categoría no suele ser capaz de ordenar las lealtades y asistencias religiosas. Una Iglesia es latina porque la mayoría de los miembros de la congregación proviene de tal latitud geográfica (menos secularizada que la región europea), no porque se generen discursos que proclamen lo latino como una categoría 
relevante a la hora de orientar los procesos de evangelización, construir Iglesias o se generen relatos acerca del papel histórico-cosmológico reservado a los latinoamericanos dentro del plan divino del Dios creador. La identidad latina en España, al menos por ahora, no es una identidad étnica, sino una categoría de identificación gregaria de la identidad nacional $y / o$ regional que toma relevancia asistemática $y$ contextuadamente cuando el interlocutor es el español. Aquí asistimos a la eterna paradoja de contraste entre identidad auto-adscrita y atribuida. Para los españoles, las Iglesias son latinas en cuantos están compuestas por población latinoamericana, en cambio, los categorizados como latinos, con grandes diferencias culturales y nacionales entre sí, apenas perciben la latinización de las Iglesias ya que el concepto de latino no juega el papel preeminente en sus identidades colectivas que los españoles asumen.

En el caso de los gitanos, en cambio, la identidad étnica si supone una categoría de adscripción subjetivamente relevante. Las Iglesias son mayoritariamente Iglesias Gitanas, con pastores gitanos y miembros de la congregación con identidad gitana. Pero todo ello no quiere decir que no existan Iglesias mixtas, compartidas con nacionales no gitanos, o Iglesias con miembros de países latinomericanos y población gitana. La etnicidad, diferencia cultural o la identidad nacional no siempre es el elemento clave que delinea las fronteras sociales en las convivencias intergrupales ${ }^{6}$, y no deben minusvalorarse las situaciones de desborde de las fronteras sociales en el fenómeno de contacto intergrupal. No obstante, en tanto en cuanto las fronteras culturales, étnicas y nacionales siguen teniendo relevancia a la hora de orientar el contacto intergrupal, la composición de los centros religiones tiende a seguir la delineación de las mismas. El nivel de integración diferencial de los individuos dentro de tales minorías se configura como el factor principal que habilita los fenómenos de contacto intergrupal en los centros religiosos. Así, la mayoría de la población latinoamericana, en general menos estigmatizada que la población gitana, tiende más que esta a compartir espacio de culto evangélico con miembros de la mayoría étnica española. Situación que, en lo relativo a los gitanos, se revierte en

6 Por ejemplo, a veces el eje pragmático, como el compartir una misma lengua transnacionalmente, ya sea el portugués, el inglés o cualquier otra, también actúa como principio de atracción al mismo centro de poblaciones étnica y/o nacionalmente heterogéneas. 
algunas zonas del Sur de España, en especial en las localidades donde existen convivencias interétnicas generacionales y aparecen recurrentemente congregaciones étnicamente mixtas payas-gitanas (Cantón Delgado, 2003). Asimismo, algunos gitanos, en especial aunque no únicamente aquellos cuyas trayectorias o aspiraciones de movilidad social ascendente y/o niveles de integración mayor, abandonan la Iglesias Evangélica de Filadelfia o Iglesia Gitana por su asfixiante y tradicional etnicidad y se vinculan a otros cultos asimismo gitanos, "mixtos" o no gitanos que les permiten desplegar una etnicidad alternativa o no tradicional. Dentro de la propias Iglesias Gitanas para terminar, existen ejes intra o subétnicos que también determinan la asistencia desagregada a los cultos y juegan un papel esencial a la hora de articular la asistencia selectiva a determinados centros religiosos y no a otros, como el status socioeconómico de los miembros de la congregación o los vínculos familiares del pastor y/o los varones más distinguidos de la comunidad religiosa.

\section{CONCLUSIONES}

El presente trabajo ha buscado desarrollar una de las líneas de investigación implícitas en el programa de investigación de Pérez-Agote, abordando la relaciones entre religión y cultura en dos poblaciones en situación de minoría social particulares: los musulmanes y evangélicospentecostales en España.

Las religiones musulmanas y evangélico-pentecostales tienden a funcionar con principios diferentes de reproducción, y en consecuencia con lógicas distintas de interacción entre cultura y religión. El enraizamiento histórico de la religión musulmana con las diversas culturas locales contrasta con las "modernas" prácticas de apropiación e hibridación de los evangélicos pentecostales. Pero de nuevo, tan relevante como las lógicas internas de las diferentes religiones son las poblaciones en las que tales universos se expresan. Así, volvamos a recordar, el grado de enraizamiento (musulmanes) e hibridación (evangélicos-pentecostales), o en otro lenguaje, el grado de in o desdiferenciación de las esferas religión-cultura, no es homogéneo entre las diferentes poblaciones musulmanas y evangélicas. En las poblaciones con identidad musulmana, el grado de des-diferenciación entre cultura y religión no es ni mucho menos el mismo en origen, aunque tienda a ser más bajo en líneas generales que, por ejemplo, el del catolicismo y 
cultura en España en la actualidad. También hemos visto que, entre otros, la variable generación migratoria y los contextos de las sociedades de acogida juegan un papel fundamental. En las poblaciones con identidad evangélica, la relevancia de la etnicidad en la vida social, como por ejemplo para buena parte de la población gitana, también ocupa un lugar central en el grado de apropiación cultural de las religiones por parte de las poblaciones conversas. De nuevo, pese a que se puede decir que en líneas generales la etnicidad gitana tiende a ser, como consecuencia de los amplios e intensos proceso de estigmatización por parte de la sociedad mayoritaria, más fronteriza que otras etnicidades en la vida social, existen diferentes regiones del país, véase ciertas regiones de Andalucía como Jerez de la Frontera, donde la "gitaneidad" no marca una frontera tan clara y concisa tendiendo a diluirse en el seno de identidades más híbridas y pluriétnicas.

Dicho todo esto, la pregunta implícita en la formulación de la relación entre la esfera religiosa y cultural en minorías - ¿es necesario un ligamen entre cultura y religión para la permanencia de la segunda en situación de minoría socioreligiosa?- no puede responderse en abstracto. Dependerá en buena medida del grado de relevancia de la(s) cultura(s) de la(s) minoría(s), y estas no pueden plantearse como bloques compactos y homogéneos sobre los que pensar tal interacción. La respuesta planteada en el texto, por tanto, es la siguiente: cuanto más relevantes sean ciertos rasgos culturales para la vida de los grupos, subgrupos e individuos, la religión deberá desdiferenciarse para la religión evangélica o quedar desdiferenciada-re-desdiferenciarse para la religión musulmana, si quiere permanecer relevante. El grado en que la adscripción cultural sea un parte concomitante del sentido de frontera social es uno de los factores que más determinará cuanto de relevante es una cultura en la subjetividad de los individuos, grupos y comunidades. Cuanto más estigmatizada y excluida una identidad cultural se presente, pongamos de nuevo el caso de los marroquíes o los gitanos, mayor importancia subjetiva tendrá tal identidad para los miembros de dicho grupo, ya que tal adscripción será uno de los pilares que ordenen y guien las pautas del contacto intercultural. Igualmente, dentro de tales grupos siempre existirán poblaciones con mayor capacidad para descentrar los estereotipos negativos y desestigmatizarse que otros, lo que dará lugar a re-significaciones de la identidad cultural y estrategias conciliadoras para con la población 
mayoritaria. Estas prácticas encuentran en la dimensión religiosa uno de los espacios en el que expresarse, como hemos visto para el caso de los musulmanes que promueven un Islam Español, los evangélicos latinos y gitanos que asisten a congregaciones mixtas o los centros religiosos evangélicos que tratan de acomodar población étnica o nacionalmente marcada en Iglesias que promueven una identidad no marcada o pretendidamente neutra. En determinados contextos, además, como es el caso de algunas teologías de la prosperidad pentecostales, las resignificaciones y estrategias conciliadoras pueden llegar a generar un fenómeno singular. Aquí las relaciones cultura y religión pueden tomar paradójicamente el sentido contrario; la religión, se acompasa con procesos de perdida de rasgos culturales e identidades nacionales/étnicas con la finalidad de conseguir una integración social plena, ascenso social y/o éxito económico. Para finalizar, señalar que en la medida en los rasgos culturales e identidades diferenciales, pierdan importancia subjetiva para los individuos, subgrupos y grupos, la religión no necesitará, ni tampoco podrá, anclarse en la cultura para mantener su vigorosidad, y deberá buscar, seguro con mayor incertidumbre, nuevas maneras de permanecer prioritaria en la vida de los individuos y hacerse relevante en el mundo social.

\section{BIBLIOGRAFÍA}

Álvarez-Benavides, A., 2013, “Procesos intergeneracionales de integración/marginalización y de (re)articulación de la identidad colectiva. Aplicación al caso de la inmigración marroquí en la Comunidad Autónoma de Madrid". Tesis Doctoral inédita, Universidad Complutense de Madrid, Madrid. Disponible en: http://eprints.ucm.es/20040/1/T34317.pdf. Última consulta: 1 de Octubre de 2015.

Barrett, D. B., Johnson, T. M., 2004, "Annual statistical table on global mission: 2004", en International Bulletin of Missionary Research, vol. 28/1, pp. 24-25.

Berger, P. L., 1967, The sacred canopy. Elements of a Sociological Theory of Religion, Anchor Doubleday, New York.

Berger, P., 2001, "Reflections on the sociology of religion today", en Sociology of Religion, pp. 443-454.

Berger P., Luckmann, T., 1968, La construcción social de la realidad, Amorrortu, Buenos Aires. 
Bruce, S., 1996, Religion in the modern world: From cathedrals to cults, Oxford University Press, Oxford.

Cantón Delgado, M., 1998, Bautizados en fuego: Protestantes, discursos de conversión y política en Guatemala (1989-1993), Centro de Investigaciones Regionales de Mesoamérica, Guatemala.

Cantón Delgado, M., 2003, “Creencias protestantes, estrategias gitanas. El Evangelismo de las Iglesias de Filadelfia en el Sur de España", en RDTP, vol. LVIII/2, pp. 179- 200.

Cantón Delgado, M., Montel, C. M., Baena, S. M., Cabezas, I. M., 2004, Gitanos pentecostales. Una mirada antropológica a la Iglesia Filadelfia en Andalucía, Signatura Demos, Sevilla.

Casanova, J., 1994, Public Religion in the Modern World, University of Chicago, Chicago.

Davie, G., 1994, Religion in Britain since 1945: Believing without belonging, Wiley-Blackwell, Oxford.

Dobbelaere, K., 1981, "Trend Report Secularization: A Multi-Dimensional Concept", en Current Sociology, Vol. 29/2, pp. 3-153.

Dobbelaere, K., 2008, "La secularización: teoría e investigación", en A. Pérez-Agote y J. Santiago (Eds.), Religión y política en la sociedad, Editorial Complutense, Madrid, pp. 17-34.

Dobbelaere, K., Pérez-Agote, A. (Eds.), 2015, The Intimate. Polity and the Catholic Church: Laws about Life, Death and the Family in So-called Catholic Countries, Vol. 15, Leuven University Press, Leuven.

Griera, M., 2012, "Public policies, interfaith associations and religious minorities: a new policy paradigm? Evidence from the case of Barcelona", en Social Compass, Vol. 59/4, pp. 570-587.

Hervieu-Léger, D., 2003, Catholicisme, la fin d'un monde, Bayard, Paris.

Hervieu-Léger, D., 2005, "Bricolage vaut-il dissémination? Quelques réflexions sur l'opérationnalité sociologique d'une métaphore problématique", en Social Compass, 52(3), pp. 295-308.

Hollenwenger, W. J., 1972, The Pentecostals: The charismatic movement in the Churches, SCM Press Ltd., London.

Jacobson, J., 1997, "Religion and ethnicity: dual and alternative sources of identity among young British Pakistanis", en Ethnic and Racial Studies, vol. 20/2, pp. 238-256.

Lamine, A. S., 2014, "Stratégies, différenciations et compromis : vers une grammaire de la conflictualité à dimension religieuse", en A. S. 
Lamine (Ed.), Quand le religieux fait conflit. Désaccords, négociations ou arrangements, Presses Universitaires de Rennes, Rennes, pp. 213234.

Luckmann, T., 1967, The invisible religion: The problem of religion in modern society, Macmillan, New York.

Martin, D., 1978, A general theory of secularization, Blackwell, Oxford.

Martin, D., 1990, Tongues of Fire: The Explosion of Pentecostalism in Latin America, Blackwell, Oxford.

Pérez-Agote, A., 2008, "Altar y trono: sociología histórica en las relaciones Iglesia-Estado en España", en A. Pérez-Agote y J. Santiago (Eds.), Religión y política en la sociedad, Editorial Complutense, Madrid, pp. 87-128.

Pérez-Agote, A., 2010, "Religious change in Spain", en Social Compass, Vol. 57/2, pp. 224-234.

Pérez-Agote, A., 2012a, (Ed.) Portraits du catholicisme. Une comparaison européenne, Presses Universitaires de Rennes, Rennes.

Pérez-Agote, A., 2012b, Cambio religioso en España: los avatares de la secularización, CIS, Madrid.

Pérez-Agote, A., 2014, "The notion of secularization: Drawing the boundaries of its contemporary scientific validity", en Current Sociology, Vol. 62/6, pp. 886-904.

Pérez-Agote, A., Santiago, J., 2005, La situación de la religión en España a principios del siglo XXI, CIS, Madrid.

Pérez-Agote, A., Santiago, J., 2009, La Nueva Pluralidad Religiosa, Ministerio de Justicia, Madrid.

Pérez- Agote, A., Santiago, J., Montañés, A. (2015), "The Catholic church faces ethical challenges in Spain. The regulation of abortion", en K. Dobbelaere y A. Pérez-Agote (Eds.), The Intimate. Polity and the Catholic Church: Laws about Life, Death and the Family in So-called Catholic Countries, Vol. 15, Leuven, Leuven University Press, pp. 155198.

Stoll, D., 1990, Is Latin American Turning Protestant? The politics of Evangelical Growth, University of California Press, Oxford.

Torres, F., Carasquilla, C., Gadea, E., Meier, S., 2007, Los nuevos vecinos de la Mancomunidad del Sureste. Los inmigrantes y su inserción en Torre Pacheco, Fuente Álamo y la Unión (Murcia), Universidad de Murcia, Murcia. 